\section{Sexualidade e gravidez na adolescência entre jovens de camadas médias do Rio de Janeiro, Brasil}

\author{
Middle-class teenage sexuality \\ and pregnancy in Rio de Janeiro, Brazil
}

Elaine Reis Brandão 1,2,3

Maria Luiza Heilborn 1

\footnotetext{
1 Instituto de Medicina Social, Universidade do Estado do Rio de Janeiro, Rio de Janeiro, Brasil.

2 Faculdade de Medicina Universidade Federal do Rio de Janeiro, Rio de Janeiro, Brasil. 3 Núcleo de Estudos de Saúde Coletiva, Universidade Federal do Rio de Janeiro, Rio de Janeiro, Brasil.

Correspondência E. R. Brandão Centro Latino-Americano em Sexualidade e Direitos Humanos, Instituto de Medicina Social, Universidade do Estado do Rio de Janeiro. Rua São Francisco Xavier 524 , bloco E, 60 andar, sala 6015 , Rio de Janeiro, $R J$ 20550-013, Brasil. elainebrandao@ims.uerj.br
}

\begin{abstract}
The subject of this paper is teenage pregnancy among middle-class youth, a topic not sufficiently studied in Brazil. The paper is based on a qualitative, socio-anthropological study of 14 middle-class families in Rio de Janeiro, Brazil, whose children have remained single, living with their parents after the child's birth. A total of 25 in-depth interviews were conducted with 6 young men and 7 young women, ages 18 to 24 , and their parents (11 mothers, one father), to examine the event in retrospect and its impact on these young people and their families. Three aspects are analyzed: difficulties young people face in internalizing contraception as a norm; late discovery of pregnancy; and how the decision to either have an abortion or give birth is made by young people and their parents. This research allows seeing teenage pregnancy as an event that hinges on the process of constructing a young person's autonomy, in which sexuality plays a prominent role. Concluding, the phenomenon should be analyzed in a specific historical and cultural context, with changes over the decades in the rules underlying the process of individualization among young people.
\end{abstract}

Pregnancy in Adolescence; Sexuality; Gender Identity

\section{Introdução}

Analisa-se o fenômeno da gravidez na adolescência nos segmentos médios cariocas, vinculando-o ao processo de individualização juvenil, entendido como o modo de construção social do jovem. Presume-se que a gravidez na adolescência possa ser tomada como um fato social revelador dos paradoxos e tensões inerentes à socialização adolescente, na qual se forja um delicado e tênue equilíbrio entre a aquisição gradativa da autonomia juvenil (sempre relativa) e a afirmação da heteronomia consoante à função educativa parental.

Nas últimas décadas, o percurso entre a infância e a idade adulta foi profundamente alterado nas sociedades ocidentais modernas. As mudanças no estatuto infantil, o redimensionamento da autoridade parental, as novas normas educativas, as transformações nas relações de gênero e entre gerações compõem novo cenário social e familiar. A extensão da escolarização e dificuldades de inserção e permanência no mercado de trabalho acentuam a dependência dos jovens em relação aos pais. Certos autores designam esse adiamento das condições de emancipação juvenil como "prolongamento da juventude" 1,2 , tornando a estada no domicílio parental mais longa que outrora. No entanto, o alongamento da dependência familiar não se torna impeditiva ao exercício da autonomia nessa fase da vida, na qual a se- 
xualidade tem grande relevância. Compreender as regras sociais que organizam o processo de construção da autonomia juvenil na atualidade pode engendrar novo olhar aos "problemas sociais" da juventude. Uma premissa fundamental é a distinção entre duas dimensões constitutivas do processo de individualização, comumente tomadas como equivalentes: a autonomia, compreendida como autodeterminação pessoal e a independência, concebida como auto-suficiência econômica $3,4,5$. Para as gerações jovens atuais, a conquista da independência se coloca cada vez mais tardia, o que não impede que a autonomia seja uma aspiração cada vez mais precoce. Nas gerações passadas, tal autonomia estava fortemente condicionada pela emancipação financeira e residencial dos pais. Hoje, os termos dependência e autonomia podem se conjugar no percurso biográfico adolescente. Tal paradoxo forja a construção social da adolescência e juventude na contemporaneidade, tornando as relações intergeracionais na família bem mais complexas.

Mesmo considerando a diversidade social das condições de existência juvenil no Brasil, há um novo cenário cultural que permeia a transição à vida adulta: difusão de novas tecnologias de informação, hábitos de consumo, valores hedonistas, violência urbana, desagregação dos laços sociais etc. Há trabalhos produzidos no país sobre a juventude 6,7 sob perspectivas diversas: educação, mercado de trabalho, violência, participação política, que ajudam a contextualizar essa fase de vida, na qual a sexualidade e reprodução se inserem.

A gravidez na adolescência tem sido apontada como um "problema social". Parir antes dos 19 anos, décadas atrás, não se constituía em assunto de ordem pública. As alterações no padrão de fecundidade da população feminina brasileira, as redefinições na posição social da mulher, gerando novas expectativas para as jovens, no tocante à escolarização e profissionalização e o fato da maioria destes nascimentos ocorrer fora de uma relação conjugal despertam atenção para o fato.

Os argumentos correntes na literatura sobre o tema, baseados majoritariamente em investigações junto às camadas populares, enfatizam a desinformação juvenil, dificuldades de acesso aos métodos contraceptivos, a pobreza, as situações de marginalidade social que circundam tais eventos. A gravidez na adolescência é apresentada como uma perturbação à trajetória juvenil, inserida em um discurso alarmista, moralizante, normativo. Em geral, os estudos apontam o incremento das famílias monoparentais, chefiadas por mulheres, a consti- tuição de uma prole numerosa, a esterilização precoce, o abandono escolar, a precária inserção no mercado de trabalho etc. $8,9,10,11$. Tais estudos centram-se no debate sobre os riscos à saúde e à inserção social de tais jovens, sem se deter nas transformações ocorridas no processo de transição à vida adulta.

Considera-se a gravidez na adolescência sob nova perspectiva, a partir das mudanças instauradas nas relações intergeracionais, no contexto familiar e na sexualidade. Ao invés de associá-la à reprodução de padrões tradicionais de inserção à vida adulta, ela é considerada um evento contingente ao processo de autonomização juvenil. Isso significa que o processo de aprendizado e construção da autonomia pessoal nessa fase da vida pode implicar certos desdobramentos imprevistos, como a gravidez, que redundam em reordenamento da trajetória juvenil e familiar.

Problematizar tal experiência à luz do processo de individualização juvenil permite fugir do círculo vicioso que domina o debate público do tema. Relativizar o argumento da desinformação e valorizar o papel fundamental que a vivência da sexualidade exerce na construção social do jovem permite captar regras sócioculturais que condicionam o fenômeno. É particularmente na esfera da sexualidade que os jovens ensaiam formas de autonomização em relação aos pais. O exercício da sexualidade na adolescência torna-se uma via privilegiada para aquisição gradativa de liberdade e autonomia, mesmo sob o teto parental.

O conceito de sexualidade adotado é derivado das ciências sociais, expresso em um conjunto de regras sócio-culturais que modelam a experiência íntima dos sujeitos no ocidente moderno 12,13. Sua articulação com o conceito de gênero é essencial, visto ser um sistema de classificação social que organiza contrastivamente os atributos masculinos e femininos em diferentes sociedades. Assim, as experiências particulares de homens e mulheres no tocante à sexualidade e à reprodução só podem ser consideradas à luz das diferenças de gênero que conformam as representações e práticas masculinas e femininas em cada cultura.

\section{Método}

Em investigação qualitativa sócio-antropológica foram realizadas 25 entrevistas em profundidade em 2000 e 2001 com 13 jovens de camadas médias do Rio de Janeiro, Brasil, sendo seis homens e sete mulheres de 18 a 24 anos, com experiência de paternidade ou maternidade na 
adolescência, ou seja, até os vinte anos incompletos, segundo parâmetros da Organização Mundial da Saúde e com 12 pais (11 mães e 1 pai) 14 . A perspectiva metodológica privilegia 0 discurso dos entrevistados como via de acesso primordial ao universo social e simbólico que organiza a experiência subjetiva dos informantes, suas representações e práticas cotidianas.

$\mathrm{Na}$ avaliação retrospectiva da gravidez na adolescência, abordaram-se integrantes das duas gerações - a juvenil e a parental, tendo em vista ser um evento familiar. Para explorar a possibilidade do exercício da autonomia juvenil em contexto de dependência parental, priorizou-se entrevistar jovens solteiros residindo com os pais, após o nascimento das crianças. As entrevistas foram individuais e privativas, com roteiro previamente elaborado, conforme temas de investigação para cada geração. Para os jovens: contexto sócio-familiar, condições de moradia, religião, trajetória escolar, profissional, afetivo-sexual, gravidez e seus impactos na família e no relacionamento com parceiro, além das repercussões da parentalidade na juventude. Para os pais: escolaridade, trajetória ocupacional, situação conjugal, religião, renda, adolescência e namoro do(a) filho(a), impacto da notícia da gravidez, decisões posteriores, organização da família para acolher o neto, conflitos e dilemas na família, vida do(a) filho(a) antes e após gravidez, relacionamento atual com filho(a), ocorrência de discriminação/constrangimento na exposição pública do fato, avaliação da juventude na atualidade, convivência entre três gerações na família. As entrevistas duraram em média duas horas e meia a três horas, tendo sido gravadas e transcritas. Em geral, ocorreram na residência dos informantes, havendo também a observação do ambiente familiar durante as entrevistas, $o$ que permitiu captar a dinâmica do relacionamento intergeracional, a distribuição da família no espaço doméstico, a presença do(a) neto(a). As entrevistas dos jovens tinham precedência, solicitando-se sua autorização para contatar os pais. O sigilo é uma premissa ética entre pesquisador e informante, sendo mantido entre todos, principalmente entre integrantes da mesma família. Outras decisões metodológicas: recusou-se o acesso aos jovens por via institucional, fosse um serviço de saúde público ou privado, consultório médico, escola. Em geral, tais instituições e seus profissionais têm posições bastante demarcadas sobre a gravidez na adolescência, com ênfase no discurso normativo vigente, podendo interferir negativamente na relação pesquisador-entrevistado. Assim, os jovens foram localizados através de contatos informais em diferentes redes de sociabilidade.

Um breve perfil sócio-familiar dos entrevistados: a maioria possuía escolaridade superior: dez pais, entre os jovens, dois estavam formados, oito cursando faculdade e três concluindo 2o grau; seis jovens trabalhavam (três moças e três rapazes), dois deles em estágios remunerados; a idade dos pais girava entre 43 e 52 anos, exercendo ocupações como assessora de imprensa, professora (ensino fundamental e universitária), socióloga, engenheiro civil, engenheira de telecomunicações, antropóloga, cabeleireira; das 14 famílias, dez possuíam renda familiar até $\mathrm{R} \$ 5.000$ e quatro entre $\mathrm{R} \$ 10.000 \mathrm{e}$ $\mathrm{R}$ 15.000; quanto à composição familiar, seis permaneciam casados, seis eram monoparentais (viuvez ou separações) e dois recasaram; residiam em bairros da zona sul e norte da cidade, de diferentes orientações religiosas ou não adeptos à religião. As entrevistas ocorreram no período posterior ao nascimento dos bebês, cujas idades variavam de um mês a sete anos. Dois deles - um rapaz e uma moça - tinham tido uma gravidez anterior e um aborto.

A pesquisa objetivou problematizar a experiência da gravidez e parentalidade na adolescência, abordando o impacto na trajetória juvenil e respectivos contextos familiares. A análise dos dados privilegiou o contraste entre gerações (pais e filhos jovens), gêneros (rapazes e moças) e relações de parentesco (consangüíneo ou por afinidade). Os temas centrais da análise foram: iniciação afetivo-sexual, gravidez e seus desdobramentos familiares, mudanças na interação e funcionamento domésticos e apreciações juvenis e parentais sobre o fenômeno.

Essa investigação integra uma pesquisa mais ampla designada Gravidez na Adolescência: Estudo Multicêntrico sobre Jovens, Sexualidade e Reprodução no Brasil (Pesquisa GRAVAD) 15,16 tendo cumprido com as exigências éticas das pesquisas envolvendo seres humanos.

\section{Discussão dos resultados}

\section{Iniciação sexual e gravidez na adolescência}

As regras do relacionamento afetivo-sexual entre jovens se alteraram muito nas últimas décadas. Atualmente, o adolescente possui uma vida sexual, nem sempre à revelia dos pais. Os relacionamentos juvenis guardam uma esfera própria de autonomia do casal, mas também se constituem em estreita interdependência com os ditames parentais de ambos os jovens. 
A sexualidade propicia o aprendizado da autonomia, fomentando o processo de construção de si na adolescência e juventude 12,13. Compreendida como mediadora de relações sociais, ela condensa possibilidades de exercício da autonomia pessoal, tendo em vista que os contatos afetivo-sexuais juvenis encontramse menos atrelados ao casamento e mais voltados ao desenvolvimento pessoal e interação com o outro.

Estrutura-se um território próprio, íntimo, que permite ao adolescente afirmar uma identidade de gênero, mediada pelo aprendizado da sexualidade com o parceiro. Construir um vínculo afetivo-sexual, diferente da amizade, constitui-se em forte via de individualização juvenil. Nessa fase, a dedicação aos estudos é uma exigência familiar e condensa expectativas mútuas quanto à definição futura da carreira profissional. Em geral, o desempenho escolar encontra-se sob forte tutela parental. A "liberdade" experimentada na socialização afetivo-sexual pode funcionar como contrapartida à heteronomia nos estudos 17 .

Esse aprendizado relacional, no qual a lógica de gênero tem papel decisivo, requer o domínio das regras da negociação a dois, seja em uma relação estabelecida ou parceria ocasional. A gravidez pode integrar esse percurso, porque a interiorização das normas de contracepção e seu subseqüente controle são ainda incipientes.

Segundo os jovens abordados, a iniciação sexual não se restringe à primeira relação. Trata-se de um longo percurso que eles atravessam, permeado por carícias íntimas, desvelamento gradativo do próprio corpo e do corpo do parceiro, conversas, dúvidas e medos, descoberta de sensações e sentimentos novos. Fazse contínua no aprendizado que se instaura doravante, pautado pela experimentação das dimensões lúdica e erótica da sexualidade e pela interiorização dos constrangimentos parentais e sociais, em especial os de gênero.

Em nove famílias, os pais tinham conhecimento da atividade sexual do(a) filho(a), enquanto três moças e dois rapazes mantinham sua atividade sexual escondida, para se preservar de eventual aumento do controle parental ou por interdição dos pais (uma moça). A maioria dos entrevistados iniciou-se sexualmente com o(a) namorado(a), exceto duas moças e um rapaz com parceiros ocasionais. Cinco rapazes e duas moças iniciaram-se com parceiros virgens. O tempo de relacionamento do casal anterior à gravidez varia entre seis meses a dois anos, exceto um rapaz que ficava ocasionalmente com a mãe de seu filho.
Três aspectos do estudo serão discutidos: as dificuldades de adesão à norma contraceptiva, a descoberta tardia da gravidez e a tomada de decisão - aborto ou reprodução - pelos jovens e seus pais.

\section{Internalização da norma contraceptiva}

Em pesquisa francesa sobre gravidezes não previstas, Bajos et al. 18 discutem aspectos que engendram a "norma contraceptiva" vigente nas sociedades ocidentais modernas. O surgimento da contracepção médica (pílula, DIU), a liberação do aborto, a medicalização da sexualidade e da reprodução difundiram um conjunto de prescrições às mulheres, sugerindo determinado comportamento reprodutivo. Contudo, as mulheres enfrentam constrangimentos para cumprirem essas normas, advindos da permanência da hierarquia de gênero. Se o exercício da sexualidade e a decisão reprodutiva podem ser compartilhados por homens e mulheres, a gestão da contracepção continua a ser encargo feminino, ainda bastante submetido à capacidade de autodeterminação e de negociação com o parceiro. Analisando as falhas, esquecimentos ou não uso de métodos contraceptivos pelas mulheres, elas argumentam que tais injunções só podem ser compreendidas como "momentos de vulnerabilidade" em um contexto social e relacional específico. Vários aspectos são analisados nas trajetórias femininas: a relação médico-paciente que condiciona a prescrição e uso do método, a compatibilidade do método indicado com o contexto da vida afetivo-sexual feminina, as representações sobre a sexualidade (sexo como algo espontâneo, lógica emocional feminina, primado do prazer masculino), a vulnerabilidade à dominação masculina, a ambivalência do desejo de ter filhos. Assim, o recurso e a gestão da contracepção estão subordinados a tais elementos. Segundo as autoras, uma gravidez não prevista traduz as dificuldades das mulheres para acatar totalmente os constrangimentos impostos pela norma contraceptiva.

A consulta ginecológica na adolescência é um dispositivo que integra a norma contraceptiva. Trata-se de hábito difundido nos segmentos médios, uma iniciativa reveladora de posturas contrastantes no que tange à tensão entre respeito à autonomia e afirmação da heteronomia na socialização juvenil. Das entrevistadas, quatro já haviam freqüentado o ginecologista com anuência dos pais. Se há o reconhecimento da experiência sexual da filha, a presença da mãe no consultório médico é evitada, para preservar a privacidade da relação 
médico-paciente. Tal acompanhamento se restringe à sala de espera, conforme relato de uma entrevistada, que buscou a consulta para decidir o método contraceptivo antes da primeira relação sexual. Por sua vez, outra jovem que mantinha relações sexuais com o namorado sem conhecimento da família era submetida ao exame ginecológico, ao lado da mãe, impossibilitando um contato estreito entre médicopaciente.

Os jovens investigados atestam sem exceção o conhecimento dos métodos contraceptivos e terem sido advertidos pelos pais a respeito, embora os diálogos sobre sexo nas famílias abordadas nem sempre fossem explícitos. Seis rapazes e seis moças utilizavam método contraceptivo (camisinha, pílula, diafragma, coito interrompido e tabelinha) na ocasião da gravidez, de modo regular em cinco casos e irregular nos demais.

O aprendizado e domínio da contracepção na adolescência é gradual como a iniciação sexual. Não se trata de uma experiência linear, racional, incondicional. Conforme os depoimentos juvenis, o uso de contraceptivos está submetido a determinadas condições: no caso do preservativo, disposição pessoal para utilizá-lo naquele momento e tê-lo consigo, determinação/resistência no jogo que se instala entre parceiros para o convencimento à relação (des)protegida etc. Os jovens estão mais vigilantes às primeiras relações sexuais, pela expectativa que geram, do que à continuidade dos intercursos sexuais. Resultados da Pesquisa GRAVAD 16 demonstram que $70 \%$ dos entrevistados adotaram contraceptivo na primeira relação sexual. Dos jovens aqui citados, nove utilizaram proteção. As medidas contraceptivas ou de proteção às DSTs também variam se os contatos sexuais se dão no âmbito de relacionamento amoroso ou ocasional. Os jovens tendem a ser menos vigilantes quando estão em relacionamentos duradouros. Luker 9 discorda que o não uso do método seja falta de "responsabilidade". Para ela isso pode representar, na verdade, uma certa negociação entre parceiros sobre o significado da relação, denotando "compromisso" e "prova de afeto". Na mesma direção, Bajos et al. 18 afirmam que "correr o risco" pode fazer sentido e trazer cumplicidade à relação, ou seja, é um ato que pode ser "relacionalmente racional".

O domínio da contracepção inscreve-se em um processo de aprendizado e de tomada de decisões no qual o conhecimento dos métodos não é decisivo. Em pesquisa sobre comportamento sexual da população brasileira, Berquó 19 reafirma a tese de que o conhecimento ne- cessariamente não predispõe à mudança de comportamento. Há intensa difusão de informações a esse respeito pela mídia, escolas, serviços de saúde, ONGs. Espera-se que a incorporação juvenil da postura contraceptiva seja automática, principalmente entre jovens escolarizados. Pressupõe-se que o acesso à informação transforme de imediato as práticas sexuais juvenis, instaurando uma conduta de auto-proteção que eliminaria possíveis riscos. $\mathrm{O}$ manejo e a introdução dos métodos são lentos, exigem discussão entre os parceiros, autoconfiança, apoio social. Tal determinação e disciplina dificilmente são compatíveis com o domínio dos "primeiros passos" sexuais.

Esse aprendizado gradual das regras sociais que organizam o relacionamento afetivo-sexual entre homens e mulheres, das quais a contracepção e a proteção às DSTs são partes integrantes, contrasta-se com uma acepção muito difundida da sexualidade como algo "natural", "espontâneo", não racional ou passível de controle. Tal percepção foi encontrada entre os jovens e na geração parental. Uma moça expressa: "porque ele ficou insistindo, sabe... a gente não é de ferro [rindo], a gente pensa, raciocina, mas não é de ferro". Uma mãe ao comentar sobre o namoro da filha, que redundou na gravidez, exprime: "não foi uma coisa provocada. Talvez não tenha sido programada, nem intencional. (...) Aconteceu”.

Ao contar sobre a relação sexual que ocasionou a gravidez, duas jovens e um rapaz explicitam situações que denotam descuido: havia camisinha no quarto mas não a usaram; usaram-na na primeira relação sexual daquele encontro mas não nas subseqüentes; não a usaram naquela ocasião, embora uso de preservativo fosse uma regra do casal. A descrição dos envolvimentos afetivo-sexuais juvenis aponta dificuldades na questão contraceptiva, captadas em dez (quatro moças e seis rapazes) depoimentos que revelam a adoção de métodos pouco seguros como coito interrompido e tabelinha, o uso descontínuo da camisinha ou pílula, alegações de rompimento do preservativo, esquecimento de ingestão da pílula, falta de proteção em intervalo para troca de pílula. Um rapaz narra que houve atraso menstrual prévio à gravidez, que deixou o casal temeroso, sendo realizado exame, com resultado negativo. No entanto, tais "sustos" não foram suficientes para reverter a conduta contraceptiva deste casal, que engravidou posteriormente.

Dois rapazes e uma moça atestaram o uso regular de contraceptivos nas relações sexuais (camisinha, pílula e diafragma). No entanto, os esquecimentos ou falhas contraceptivas tam- 
bém ocorrem. As justificativas apontadas por eles para a gravidez são: rompimento da camisinha; falha na cobertura do diafragma, que não apresenta $100 \%$ de proteção; esquecimento da pílula, embora a namorada afirme ao entrevistado não ter esquecido. Nesses casos, a tensão entre exercício sexual, contracepção e ocorrência da gravidez é atenuada em função de postura responsável que os jovens reivindicam para si, comprovada pelo uso contínuo de contraceptivos que, no entanto, falharam - no caso da camisinha e diafragma. Quanto à pílula, não há como avaliar se houve esquecimento ou falha na cobertura.

Distintas representações sociais sobre a pílula foram encontradas, considerando-se as duas gerações de mulheres. Nas mais jovens, a pílula não é revestida do espírito de contestação e liberdade, próprios ao contexto dos anos 60 e 70, no qual ela emergiu. Três delas associam-na a algo que faz mal à saúde, engorda ou deforma o corpo, com posições contrárias à ingestão de hormônios, influenciadas por pressupostos ecológicos/naturalistas, estéticos ou científicos. Por sua vez, uma mãe, cuja nora interrompeu o uso da pílula por estar engordando expressa: “...nunca deixei de tomar pílula. Sou da geração pílula, a gente não deixava de tomar pílula. Ninguém dizia que fazia um mal terrível. Àquela época, a pílula era o máximo...". Decerto essa rejeição que a pílula desperta, também notada no contexto francês 18, somada aos imperativos estéticos de um corpo perfeito podem comprometer a utilização do método entre as jovens.

Aderir a uma postura contraceptiva também está relacionada ao fato do exercício sexual juvenil ser ou não do conhecimento da família. Nos nove casos em que os pais/mães estão a par da vida sexual dos filhos, dúvidas, agendamento de consultas médicas e realização de exames diversos são prontamente resolvidos. Quando a prática sexual dos filhos não é discutida na família, o gerenciamento da contracepção à revelia dos pais torna-se mais difícil, conforme narram cinco entrevistados. No entanto, o fato dos pais estarem cientes e recomendarem a utilização de contraceptivos não significa que isso seja feito. As mães de três rapazes e uma moça declararam-se surpresas com a gravidez, pois supunham que os filhos estivessem usando pílula ou camisinha.

O controle da contracepção é uma experiência subjetiva, que se aprende e se adquire com o tempo, no decurso dos relacionamentos afetivo-sexuais, permeados pelas assimetrias de gênero. Raramente se instaura $a$ priori, pois não se reveste de decisões unilaterais, embora freqüentemente tomadas pelas mulheres.

\section{A descoberta tardia da gravidez}

A percepção feminina dos primeiros sinais de uma gravidez requer certo tempo. Não é uma dedução imediata da relação sexual desprotegida ou do esquecimento da pílula. Se fosse, a utilização da pílula do dia seguinte seria um recurso muito mais difundido entre nós. Uma jovem e as namoradas de três rapazes entrevistados só descobriram ou confirmaram a gravidez após o primeiro trimestre. Tal percepção encontra-se condicionada a certos aspectos, conforme os depoimentos analisados: não exercício regular da sexualidade, com relações esporádicas quando não se tem parceiro fixo; adesão periódica às dietas alimentares para emagrecimento, freqüentes entre adolescentes, acarretando alternância de peso e, por vezes, ingestão de medicamentos; sangramentos confundidos com ciclos menstruais, que podem ser irregulares nessa idade (14/15 anos). Há relatos de jovens que passam alguns meses sem menstruar. Todos estes aspectos dificultam a percepção das mudanças corporais, interferindo diretamente na descoberta tardia da gravidez. Explicitar tal desconfiança ao namorado e/ou aos pais é outra etapa lenta, que também possui uma temporalidade própria, contribuindo para a revelação tardia da gravidez ou de sua suspeita na família.

O exercício sexual, a contracepção, a percepção e o enfrentamento da gravidez são momentos inscritos em um processo subjetivo e peculiar de individualização, de crescimento e aprendizado da responsabilidade e da autonomia. São adolescentes em processo de construção de si, aprendendo na relação com os pais, pares e parceiros afetivo-sexuais a se tornarem pessoas adultas. Esse processo é passível de avanços e recuos, hesitações, deslocamentos entre posições mais firmes, indicadoras de autonomia, e mais vulneráveis.

Inscrito na dinâmica de autonomização pessoal na adolescência, o fenômeno da gravidez na adolescência perde seu caráter de exceção. Embora inesperado, ele pode integrar o percurso biográfico adolescente, que congrega um aprendizado gradual das regras sociais que estruturam as relações entre gêneros e entre as gerações, as quais incidem diretamente em sua socialização sexual, na qual o domínio da contracepção se situa.

\section{Aborto ou reprodução}

A tomada de decisão que uma gravidez inesperada na adolescência impõe exemplifica a tensão entre autonomia e heteronomia referida. 
Ao considerar as deliberações entre jovens e seus pais para decidir a solução diante da gravidez - aborto ou levá-la a termo - os dilemas vivenciados pelas duas gerações ficam patentes. Os jovens sabem que têm poucas chances de viabilizá-las sem apoio dos pais. Os pais, por sua vez, ao vislumbrarem o futuro dos filhos imiscuído a uma gravidez precoce, se deparam com a necessidade de respeitarem as posições e decisões dos filhos, ainda muito jovens e seus dependentes. Nem sempre as posturas de filhos e pais são concordantes ou chegam a ser resolvidas a um bom termo.

A discussão sobre levar ou não a gestação a termo nem existiu em muitos casos, por razões distintas. Diante da gravidez, cinco moças e três rapazes decidiram ter os filhos, nem cogitando o aborto. Dentre seus respectivos parceiros, dois rapazes mencionaram a opção do aborto, mas isso não foi motivo de conflito entre o casal. Elas tinham uma posição contrária e eles a respeitaram. O restante posicionava-se também contrários ao aborto. Os pais destas cinco moças tinham a mesma opinião, ao passo que no caso dos familiares dos rapazes, eles terminam por acatar uma decisão gestada pela moça e seus pais. No extremo oposto, ao tomarem conhecimento da gravidez, dois jovens (um rapaz e uma moça) mostraram-se favoráveis ao aborto desde o primeiro momento. Essa alternativa foi compartilhada com os respectivos pais e parceiros. Posteriormente, essa escolha foi descartada pelo tempo avançado de gestação.

Quando as primeiras manifestações dos filhos coincidem com a posição dos pais não há o que discutir. O debate se desloca para outras decisões relativas ao futuro. Ambas as gerações concordam numa decisão central, atenuando os conflitos.

Quando os jovens não possuem uma posição prévia, decerto a decisão será tomada em família, mediante discussões entre o jovem casal e seus pais. A alternativa do aborto foi cogitada pela geração parental em quatro casos (uma moça e três rapazes), sem imposição aos filhos ou parceiros. Alguns pais respeitaram a decisão juvenil, embora contrários à opção da gravidez a termo. Os jovens relatam se sentirem mais seguros com o apoio parental.

Em duas famílias, o aborto foi avaliado pelos pais e discutido com os jovens e especialistas, especialmente seus riscos no segundo trimestre da gestação. Em outra, a ponderação do aborto adveio do fato da jovem ser muito nova (14 anos) e desejar ter a criança, apesar de sua idade. Sua escolha foi respeitada pelos adultos.

A tomada de decisão da gestante ou do casal, com o apoio de suas famílias - qualquer que seja a opção - tende a ser estruturante para os jovens e lhes possibilita uma referência neste momento conturbado. O enfrentamento do processo de decisão integra a experiência de amadurecimento/crescimento pessoal, embora o jovem casal ainda não tenha plena consciência de todos os desdobramentos subseqüentes à decisão tomada.

Quando surgem discordâncias entre o desejo dos jovens e o de seus pais, os conflitos se agravam. Qualquer que seja a escolha do jovem dificilmente ele terá condições de viabilizá-la sem ajuda da família. Para os pais, esse é um momento de dúvidas e dilemas em relação ao futuro dos filhos. Em uma família, a manifestação feminina da vontade de ter o filho, compartilhada com o parceiro, não foi suficiente para que prevalecesse a decisão. Alguns jovens ficam muito indecisos e temerosos, tornandose vulneráveis às opiniões de familiares e médicos, convocados a opinar. O recurso a especialistas da medicina pode ser acionado pelos pais para auxílio no convencimento aos filhos, nas duas direções: para manter a gravidez e para o aborto. Adotando a solução que consideram ser a melhor para os filhos, alguns pais conseguem convencê-los a fazer um aborto, situação encontrada em um caso analisado. Essa entrevistada fez um aborto a conselho dos pais, sofrendo pressão do namorado, contrário à decisão da família dela, e terminou engravidando três meses depois. Ela estava ciente de que a alternativa de interrupção não poderia ser novamente acionada, em razão das restrições médicas de um segundo aborto em curto intervalo de tempo. Em dois outros casos, a alternativa do aborto foi imposta, sem êxito. Esses dois rapazes relatam ter sentido alívio pela impossibilidade do aborto, pelo tempo gestacional avançado. Em um caso, a imposição adveio da mãe do rapaz, em outro da mãe da gestante.

Essa situação-limite ilustra o cerne da tensão que perpassa o processo de socialização juvenil. Os filhos podem ter decisões próprias ou acordadas com os parceiros, mas dificilmente terão condições de efetivá-las sem os pais. Estes, por sua vez, podem avaliar que uma solução é preferível à outra, mas é cada vez mais difícil impô-la aos filhos. Por todas as injunções presentes nas relações intergeracionais na contemporaneidade, o respeito à privacidade e autonomia dos filhos tende a ser uma norma imperante nesses segmentos sociais. Se há discordância entre as gerações no tocante à resolução da gravidez, as estratégias parentais de convencimento dos filhos precisam ser cada vez mais sutis. Isso não se constitui tarefa fácil em se tratando de tudo que está em jogo para a 
trajetória juvenil e para o grupo familiar que, na hipótese do nascimento do neto, precisará se reorganizar do ponto de vista financeiro, doméstico e espacial para acolhê-lo.

Por mais difícil que seja uma gravidez na adolescência, presume-se que ambas as decisões - aborto ou reprodução - podem ser incorporadas ao processo de construção da identidade juvenil, quando vividas como alternativas escolhidas e assumidas por eles e não impostas por terceiros.

\section{A gravidez no cenário familiar}

Não há dúvida de que a parentalidade na adolescência agrava sobremaneira a dependência familiar dos jovens, em todos os sentidos. O apoio financeiro, doméstico e afetivo permite que eles superem muitos obstáculos e enfrentem os desafios da carreira escolar e profissional, da convivência com o parceiro e familiares dele. As diferenças de gênero, após o nascimento dos filhos, tendem a se tornar mais expressivas, provocando inúmeras desavenças entre os jovens casais. A sobrecarga feminina no exercício da maternidade demonstra a persistência de hierarquias de gênero, mesmo entre gerações mais jovens. Certamente, essa situação agrava as cobranças na relação intergeracional, tornando-a mais conturbada. Novas negociações devem ser efetivadas entre jovens e seus pais para viabilizar em conjunto os cuidados do recém-nascido. Ocorrem inúmeros conflitos na família, decorrentes do descumprimento das tarefas domésticas estipuladas para as jovens, da convivência do neto com outras crianças da casa, da presença cotidiana do(a) parceiro(a) da(o) filha(o) no ambiente familiar, de interdições aos parceiros mal quistos. Uma nova gestão doméstica é instalada no ajuste das obrigações e direitos de cada um. No entanto, a despeito das desavenças, na maioria das famílias prevalece a decisão parental de que o nascimento da criança não deve impedir o curso previsto para a trajetória juvenil. Em geral, a condição de dependência juvenil não se torna impeditiva do exercício da autonomia, acepção compartilhada pelos jovens e seus pais. São promovidas adaptações, reajustes frente à chegada do neto, mas há um compromisso fundamental entre pais e filhos no sentido da manutenção do projeto de individualização juvenil, tal qual ele vinha sendo delineado antes da gravidez. Embora a gravidez na adolescência seja um evento que acarrete profundas alterações na vida dos envolvidos, em distintos segmentos sociais, não há uma ruptura ou in- flexão significativa nas trajetórias juvenis analisadas. Apesar das dificuldades, o apoio parental busca preservar o projeto de individualização dos filhos.

Comparar a experiência da gravidez na adolescência em diferentes classes sociais 11 permite compreender tal argumento. Em geral, nos segmentos populares, a gravidez promove mudanças no estatuto social dos jovens pais. Eles passam a ocupar outras posições sociais decorrentes da parentalidade e da mudança do estatuto conjugal, o que lhes atribui maior prestígio e reconhecimento social nas suas comunidades. Comumente, a parentalidade na adolescência nos estratos populares engendra um deslocamento de posição dos jovens em relação às famílias de origem, pois eles aspiram constituir suas famílias de procriação. Estabelecem um terceiro núcleo doméstico próximo ou residem junto à família de um deles, recebendo ajuda dos familiares. Simbolicamente, há nesse contexto uma certa ruptura a partir do evento da gravidez que inaugura novo período de vida, com assunção moral mas não material de novas responsabilidades relativas à prole.

Nas camadas médias, a parentalidade na adolescência não acelera o curso da vida, nem se constitui em rito de passagem à posição social de adulto. $\mathrm{O}$ estatuto social dos jovens não foi alterado, nem as posições que ocupavam nas famílias de origem. Os entrevistados privilegiam a via do "crescimento pessoal", postergando para o futuro a efetivação dos projetos profissionais e conjugais. O nascimento do filho, embora dificulte e torne bem mais problemática tal transição, sobretudo para as mulheres, que não conseguem dividir os encargos referentes aos filhos eqüitativamente com os respectivos parceiros, não impõe reformulações que coloquem em xeque tais expectativas.

Embora esses jovens se deparem com dificuldades e hesitações agravadas pela ilegitimidade social da parentalidade em tais circunstâncias - fomentada pelos estereótipos sociais sobre a "irresponsabilidade" adolescente - a possibilidade de torná-la um evento que contribui para a afirmação da identidade pessoal juvenil não pode ser desprezada.

\section{Conclusão}

A discussão sobre sexualidade e reprodução na juventude não pode ocorrer isolada do contexto sócio-cultural que modela as relações sociais nas quais os jovens estão inseridos. Sem considerar as relações intergeracionais que têm 
na família expressão particular e as relações com os pares, nas quais a iniciação afetivo-sexual ocorre, as análises tendem a revelar aspectos parciais. Compreender a dinâmica que rege a construção social de adolescentes e jovens na contemporaneidade é uma via fundamental para se discutir as trajetórias sexuais e reprodutivas juvenis em diferentes segmentos sociais. O lugar que a sexualidade ocupa no processo de autonomização juvenil, ainda hoje muito marcado pela hierarquia de gênero, tor-

\section{Resumo}

Aborda-se a gravidez na adolescência entre jovens de camadas médias, prisma pouco estudado no Brasil. Realizou-se um estudo qualitativo sócio-antropológico com 14 famílias do Rio de Janeiro, Brasil, cujos filhos permaneciam solteiros e residindo com os pais, após o nascimento da criança. Foram realizadas 25 entrevistas em profundidade com 6 rapazes $e 7$ moças entre 18 e 24 anos e seus pais (11 mães e 1 pai), para avaliação retrospectiva da gravidez e de seus impactos na trajetória juvenil e familiar. Três aspectos são analisados: as dificuldades de internalização da norma contraceptiva; a descoberta tardia da gravidez e a tomada de decisão - aborto ou reprodução - pelos jovens e seus pais. O estudo permitiu configurar a gravidez na adolescência como um evento contingente ao processo de construção da autonomia pessoal em curso nessa fase da vida, no qual a sexualidade tem grande relevância. Conclui-se que o fenômeno precisa ser compreendido em um contexto histórico e cultural específico, distinto de sua ocorrência décadas atrás, pois está marcado pelas regras que organizam o processo de individualização juvenil na contemporaneidade.

Sexualidade; Gravidez na Adolescência; Identidade de Gênero na-se a chave para uma leitura mais acurada do fenômeno da gravidez na adolescência.

Decorre daí a complexidade da proposta de uma política de prevenção à gravidez na adolescência, tendo em vista que ela não pode estar apenas ancorada na transmissão de informações relativas à contracepção e proteção às DSTs/AIDS. Ela deve incorporar a lógica que orienta a experimentação sexual com o parceiro como via principal para a construção gradativa da autonomia pessoal, mesmo em contextos de dependência parental.

\section{Colaboradores}

E. R. Brandão conduziu a investigação e redigiu o artigo. M. L. Heilborn orientou a pesquisa, fazendo a revisão final do texto.

\section{Agradecimentos}

A investigação Gravidez na Adolescência: Estudo Multicêntrico sobre Jovens, Sexualidade e Reprodução no Brasil (Pesquisa GRAVAD) foi elaborada por Maria Luiza Heilborn (Instituto de Medicina Social, Universidade do Estado do Rio de Janeiro - IMS/UERJ), Michel Bozon (Institute National d'Études Démographiques - INED, França), Estela M. L. Aquino (Programa Integrado de Pesquisa e Cooperação Técnica em Gênero e Saúde/Universidade Federal da Bahia MUSA/UFBA) e Daniela Knauth (Núcleo de Antropologia do Corpo e Saúde/Universidade Federal do Rio Grande do Sul - NUPACS/UFRGS). O estudo foi realizado por três centros: Programa em Gênero, Sexualidade e Saúde (IMS/UERJ), MUSA/UFBA e NUPACS/ UFRGS. Os principais resultados do inquérito encontram-se publicados no livro O Aprendizado da Sexualidade: Reprodução e Trajetórias Sociais de Jovens Brasileiros (Rio de Janeiro: Garamond; 2006), onde podem ser obtidas informações sobre a composição detalhada da equipe de pesquisadores. Agradecemos também à Fundação Ford, ao programa de bolsas do Conselho Nacional de Desenvolvimento Científico e Tecnológico e à Coordenação de Aperfeiçoamento de Pessoal de Nível Superior. 


\section{Referências}

1. Cavalli A, Galland O. L'allongement de la jeunesse. Paris: Actes Sud; 1993.

2. Galland O. Sociologie de la jeunesse. Paris: Armand Colin; 1997.

3. Renaut A. L'ère de l'individu. Contribution à une histoire de la subjectivité. Paris: Gallimard; 1989.

4. Chaland K. Pour un usage sociologique de la double généalogie philosophique de l'individualisme. In: Singly F, editor. Être soi d'un âge à l'autre. Famille et individualisation. Paris: L'Harmattan; 2001. p. 31-43.

5. Singly F. Penser autrement la jeunesse. Lien Social et Politiques - RIAC 2000; 43:9-21.

6. Novaes R, Vannuchi P, organizadores. Juventude e sociedade: trabalho, educação, cultura e participação. São Paulo: Fundação Perseu Abramo; 2004.

7. Abramo HW, Branco PP, organizadores. Retratos da juventude brasileira: análise de uma pesquisa nacional. São Paulo: Fundação Perseu Abramo/ Instituto Cidadania; 2005.

8. Monteiro DLM, Cunha AA, Bastos AC, organizadores. Gravidez na adolescência. Rio de Janeiro: Revinter; 1998.

9. Luker K. Dubious conceptions. The politics of teenage pregnancy. Cambridge: Harvard University Press; 1996.

10. Vieira EM, Fernandes MEL, Bailey P, McKay A, organizadores. Seminário gravidez na adolescência. São Paulo: Associação Saúde da Família; 1998.

11. Brandão ER. Gravidez na adolescência: um balanço bibliográfico. In: Heilborn ML, Aquino EML, Knauth D, Bozon M, organizadores. O aprendizado da sexualidade: um estudo sobre reprodução e trajetórias sociais de jovens brasileiros. Rio de Janeiro: Garamond; no prelo.
12. Foucault M. História da sexualidade I. A vontade de saber. Rio de Janeiro: Graal; 1993.

13. Bozon M. Sociologia da sexualidade. Rio de Janeiro: Editora FGV; 2004.

14. Brandão ER. Individualização e vínculo familiar em camadas médias: um olhar através da gravidez na adolescência [Tese de Doutorado]. Rio de Janeiro: Instituto de Medicina Social, Universidade do Estado do Rio de Janeiro; 2003.

15. Heilborn ML, Salem T, Rohden F, Brandão E, Knauth D, Victora C, et al. Aproximações sócioantropológicas sobre a gravidez na adolescência. Horizontes Antropológicos 2002; 8:13-45.

16. Aquino EML, Heilborn ML, Knauth D, Bozon M, Almeida MC, Araújo J, et al. Adolescência e reprodução no Brasil: a heterogeneidade dos perfis sociais. Cad Saúde Pública 2003; 19 Suppl 2:S37788.

17. Cicchelli V. La construction de l'autonomie. Parents et jeunes adultes face aux études. Paris: PUF; 2001.

18. Bajos N, Ferrand M, Hassoun D. Au risque de l'échec: la contraception au quotidien. In: Bajos $\mathrm{N}$, Ferrand M et l'équipe GINÉ, editors. De la contraception à l'avortement. Sociologie des grossesses non prévues. Paris: Editions INSERM; 2002. p. 33-78.

19. Berquó E, organizador. Comportamento sexual da população brasileira e percepções do HIV/Aids. São Paulo: Centro Brasileiro de Análise e Planejamento, Programa Nacional de DST/AIDS, Ministério da Saúde; 2000.

Recebido em 09/Mai/2005

Versão final reapresentada em 12/Ago/2005 Aprovado em 24/Ago/2005 